\title{
Do insulinotropic glucose-lowering drugs do more harm than good? The hypersecretion hypothesis revisited
}

\author{
I. Rustenbeck $\cdot$ S. Baltrusch $\cdot$ M. Tiedge
}

Received: 5 March 2010 /Accepted: 26 May 2010 /Published online: 1 July 2010

(C) Springer-Verlag 2010

\begin{abstract}
Significant progress has been made in recent years in the characterisation of the signal pathways of beta cell dysfunction and death in the pathogenesis of type 2 diabetes. Glucolipotoxicity acts as an exogenous factor whereas oxidative stress and endoplasmic reticulum stress may result from the processes of signal recognition and stimulated secretion within the beta cell. The pharmacological stimulation of secretion may thus appear to be a double-edged sword: it counteracts hyperglycaemia, but may do so at the expense of beta cell mass. So, in the long run, insulinotropic glucose-lowering drugs might do more harm than good. However, much of this logic is derived by analogy from the long-held assumption that beta cell hypersecretion imposed by insulin resistance causes the absolute secretion deficit in the later course of type 2 diabetes. In this concept the beta cell has a secondary role and loss of beta cell mass is necessary for the manifestation of type 2 diabetes. Recent studies have shown that a secretion deficit can exist well before insulin resistance and that major genetic risk factors concern beta cell function. Also, the evidence for a beta cell toxic effect of insulinotropic drugs is currently inconclusive. Assuming that the insulin secretion deficit is of pathogenetic importance in a network with insulin resistance as an aggravating factor, an insulinotropic glucose-lowering drug may do
\end{abstract}

\footnotetext{
I. Rustenbeck $(\bowtie)$

Institute of Pharmacology and Toxicology,

University of Braunschweig,

Mendelssohnstrasse 1,

38106 Braunschweig, Germany

e-mail: i.rustenbeck@tu-bs.de

S. Baltrusch $\cdot$ M. Tiedge

Institute of Medical Biochemistry and Molecular Biology,

University of Rostock,

Rostock, Germany
}

more good than harm if it relieves the beta cell from the stress of glucose overstimulation and does so without inducing hypoglycaemia.

Keywords Antidiabetic drugs · Beta cell · Glucoselowering drugs $\cdot$ Hyperinsulinaemia $\cdot$ Type 2 diabetes
Abbreviations
ER Endoplasmic reticulum
GK Glucokinase
GLP-1 Glucagon-like peptide 1
UKPDS UK Prospective Diabetes Study

\section{The hypersecretion hypothesis}

The pharmacological treatment of type 2 diabetes remains a difficult task despite the availability of novel drugs. It has been known for decades that after an initial improvement of metabolic control, oral glucose-lowering drugs gradually lose their effectiveness in controlling the concentration of glucose $[1,2]$. This course of events has also been found in the UK Prospective Diabetes Study (UKPDS), in which the efficacy of oral glucose-lowering drugs and of insulin was followed up for more than 10 years. Because a gradual deterioration of metabolic control was found in all treatment arms, irrespective of the mechanism of action, it was concluded that the progression of the disease was the common underlying cause. Specifically, loss of beta cell function correlated with the deterioration of glycaemia [3-5].

In a recent 'For debate' article by Aston-Mourney and colleagues in this journal, the hypothesis was proposed that the use of insulinotropic glucose-lowering drugs would be a 
major contributing factor to the progression of type 2 diabetes [6]. Moreover, the authors integrated this view into a general theory implicating insulin hypersecretion as the central pathogenetic factor in type 2 diabetes. While in most cases the reason beta cells synthesise and secrete increased amounts of insulin is decreased responsiveness of the insulin-sensitive tissues (insulin resistance), the authors emphasise that conditions exist in which the beta cell hypersecretes in the absence of insulin resistance (e.g. by activating glucokinase mutations) and that these conditions also predispose to type 2 diabetes [7]. However, recent data in families with activating glucokinase mutations leading to neonatal hyperinsulinaemia did not provide clear evidence for increased type 2 diabetes mellitus in these patients [8].

The proposed link between insulin hypersecretion and manifestation and the progression of type 2 diabetes consists of endogenously generated beta cell damage (Fig. 1). In fact, in vitro experimentation has shown that the increased metabolism of fuel secretagogues and the increased insulin biosynthesis induce oxidative stress [9] and endoplasmic reticulum (ER) stress in the beta cell [10]. It was now hypothesised that over the years this would lead to a critical loss of beta cell mass, at least in a subset of persons in whom the stress defence mechanisms are particularly weak [6]. The prescription of an insulinotropic drug to treat newly manifested diabetes would then create a vicious cycle, the improvement of metabolic control being achieved at the expense of an accelerated loss of beta cell mass.

In fact, an observation in the recently published ADOPT (A Diabetes Outcome Progression Trial) study suggests that the above sequence of events does exist and is of clinical relevance. In that study, monotherapy with the sulfonylurea glibenclamide resulted more often in the addition of another glucose-lowering drug to maintain metabolic control than monotherapy with metformin or rosiglitazone [11]. Another piece of evidence that an increased workload makes the beta cell literally work itself to death is the improved responsiveness seen after transient inhibition of insulin [12]. This has led to the therapeutic concept of beta cell rest (see below), seemingly the opposite of the pharmacological stimulation of insulin secretion. However, a more comprehensive consideration of basic and clinical studies gives a less straightforward response to the question of whether insulinotropic drugs do more harm than good.

\section{Hypersecretion as a pathogenetic mechanism in type 2 diabetes}

In principle, the sequence of events proposed in the hypersecretion hypothesis can be regarded as a derivative

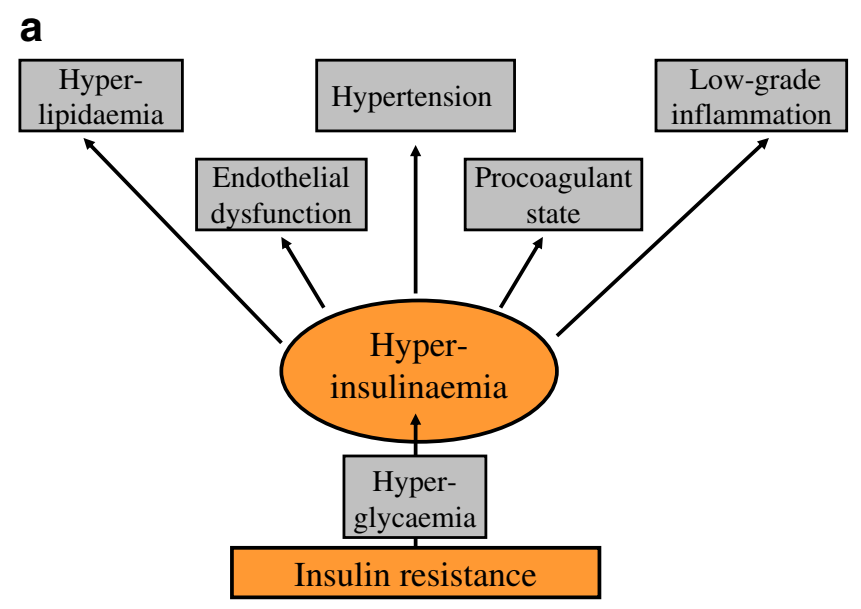

b

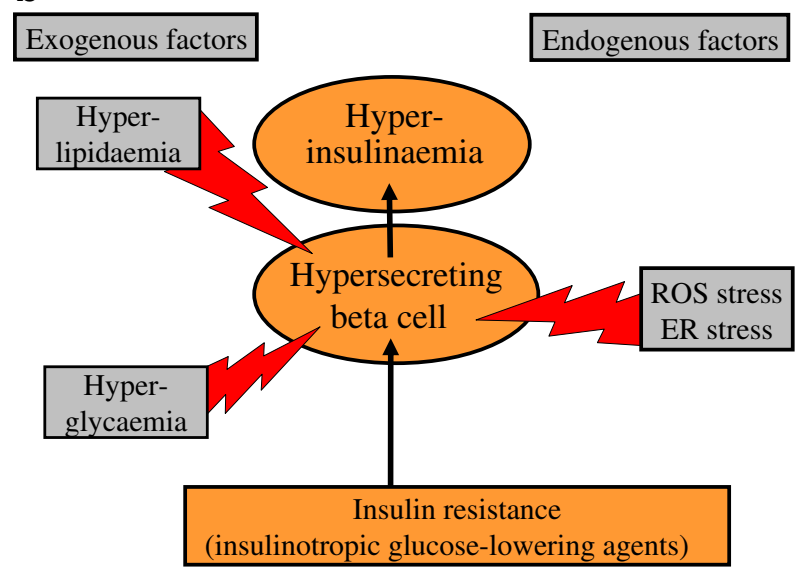

Fig. 1 The role of the beta cell within the concept of the metabolic syndrome. a The insulin resistance of the classical insulin-sensitive tissues is regarded as the underlying common cause. The link between insulin resistance and the manifold manifestations of the syndrome is hyperinsulinaemia, by which the endocrine pancreas tries to overcome the insulin resistance. The idea that a common cause exists for a variety of seemingly unrelated diseases and the central pathogenetic role of the adipose tissue in the context of the obesity epidemic in the Western world underlies the prevalence of this concept during the last 30 years. b The beta cell, which is forced to hypersecrete, is secondarily involved in the pathogenesis of type 2 diabetes within the metabolic syndrome. The process of hypersecretion is assumed to produce reactive oxygen species stress and ER stress and thus to diminish secretion capacity because of the loss of beta cell mass. Deterioration of metabolic control (hyperglycaemia and hyperlipidaemia) aggravates this loss via gluco- and lipotoxicity. It has been suggested that pharmacological enhancement of insulin secretion may induce the same sequence of events

of the insulin resistance paradigm as originally defined by Reaven [13]. Here, increased insulin secretion is also implicated, because of the central pathogenetic role of the insulin resistance-induced hyperinsulinaemia. According to Reaven's concept, which has expanded considerably over the years, hyperinsulinaemia is the common cause of the many diverse manifestations of the metabolic syndrome [14]. In this scenario, exogenous beta cell damage occurs 
which is caused by glucotoxicity as a consequence of insulin resistance and lipotoxicity as a consequence of hyperinsulinaemia (Fig. 1). Aston-Mourney et al. [6] postulate that the loss of beta cell mass is caused by mechanisms intrinsic to the beta cell. Consequently, the ability to increase the synthesis and release of insulin would be proportional to the accumulating beta cell damage, which determines the progression towards type 2 diabetes. In other words, the stronger the beta cell secretory response the more likely the manifestation of type 2 diabetes at a later time.

This is a testable hypothesis. Epidemiological evidence which was gathered to clarify the pathogenetic roles of insulin resistance and insulin secretion deficiency ought to have drawn attention to this inverse relationship. However, insulin secretion defects have been found repeatedly in nondiabetic first-degree relatives of diabetic patients irrespective of insulin resistance $[5,15]$. These studies suggest that an insulin secretion deficit is an independent risk factor for type 2 diabetes and not necessarily a consequence of longterm beta cell overwork (Fig. 2). These functional data fit the currently available set of genetic susceptibility factors for type 2 diabetes, most of which are relevant to beta cell function, not insulin action [16]. In view of this evidence,

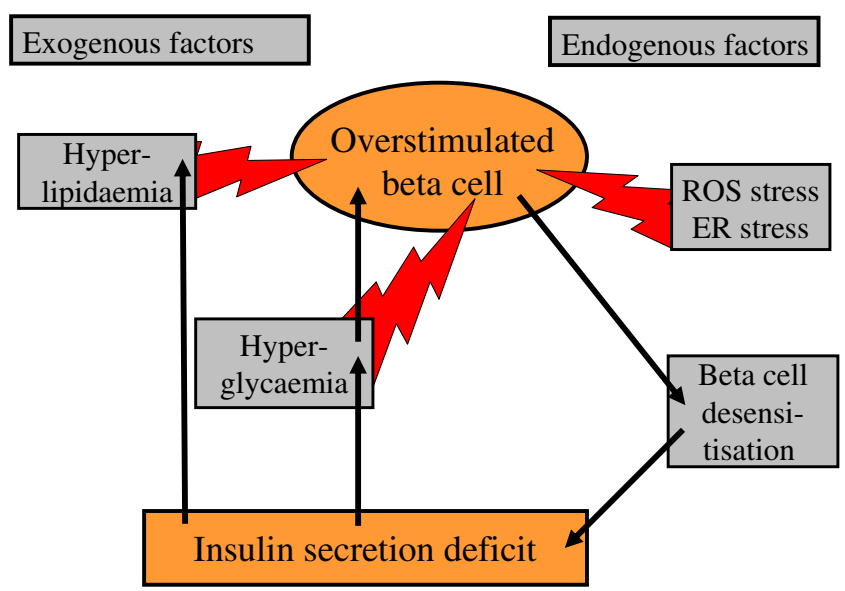

Fig. 2 The role of the beta cell within the concept of the insulin secretion deficit. Here the inability of the endocrine pancreas to respond adequately to nutrient challenges is the primary cause of type 2 diabetes. The size of the deficit is determined by the requirement for insulin and the inability of the beta cell to supply it. Of note, not only the amount of insulin as such, but also the kinetics of release decide whether the demand is met. The persistent hyperglycaemia may lead to beta cell desensitisation, which initiates a vicious circle. In this scenario the beta cell is not so much under stress from activated insulin biosynthesis but from the constantly activated signal recognition machinery. Nevertheless, an endogenous process of beta cell loss is the consequence. As in Fig. 1b, persistent hyperglycaemia and hyperlipidaemia may contribute to this loss via gluco- and lipotoxicity. In contrast to the above concept, however, the loss of beta cell mass would not be decisive for the manifestation of the disease the pathogenetic role of the metabolic syndrome has been questioned, the clinical relevance of this clustering of cardiovascular risk factors notwithstanding [17].

Of note, the view that, in the course of type 2 diabetes, glucotoxicity or lipotoxicity or a combination of both negatively affects beta cell function and viability, the latter probably by induction of apoptosis, is shared by most researchers in the field $[18,19]$. It is conceivable that there is a continuum from defective beta cell function via hyperglycaemia to beta cell desensitisation, and finally, via further increased hyperglycaemia and hyperlipidaemia, to structural beta cell damage (Fig. 2) [20]. While it is generally accepted that in the course of human type 2 diabetes a net loss of beta cell mass as such develops and contributes to disease progression [21, 22], there is no consensus about whether this loss is a prerequisite for the functional deterioration leading to manifestation of the disease [22]. A major piece of evidence in favour of the hypersecretion hypothesis would be clear evidence that the increased insulin biosynthesis has led to changes characteristic of ER stress at early stages of the disease. However, a recent investigation found only modest signs of ER stress in autoptic pancreatic samples and isolated islets from type 2 diabetic patients maintained at physiological glucose concentrations [23]. Only exposure of islets to a high glucose concentration revealed alterations of ER stress markers in islets isolated from diabetic persons, but not in those from normal persons [23].

\section{Hypersecretion caused by insulinotropic glucose-lowering drugs: long-term efficacy and beta cell effects}

The difference in the ADOPT study between the rate of secondary failure in glibenclamide-treated patients on the one hand and that in metformin- or rosiglitazone-treated patients on the other hand suggests that a loss of endogenous secretory capacity may have occurred in the glibenclamide group [11]. But even if this is the case, can it be attributed to sulfonylurea-induced hypersecretion? This assumption can be questioned since the overall increase in secretion is less impressive than widely assumed. In an authoritative pharmacology textbook edited in the not-solong ago era when the sulfonylurea receptor had not yet been identified at the molecular level, this is described as follows: 'With chronic administration [of sulfonylureas], circulating insulin levels decline to those that existed before treatment, but despite this reduction in insulin levels, reduced plasma glucose levels are maintained' and '... there is no measurable acute stimulatory effect of sulfonylureas on insulin secretion during chronic treatment' [24].

This passage reflects the conviction of many researchers at that time that extrapancreatic effects of sulfonylureas not 
only exist but are more relevant to long-term therapy than the acute insulinotropic effect $[25,26]$. This interpretation was erroneous, however, because it did not take into account the glucose dependency of the insulinotropic effect of the sulfonylureas [27, 28]. The decrease in blood glucose levels caused by the initiation of sulfonylurea therapy diminishes the efficacy and thereby masks the insulinotropic effect. The persistence of the insulinotropic effect after long-term treatment was elegantly demonstrated by expressing the plasma insulin level as a function of glucose concentration [29].

In this context, an early investigation of the so-called insulinotrophic effect of sulfonylureas is worth mentioning. Tolbutamide was applied to rats at a dosage to mimic the therapeutic situation in man; under this condition enhanced insulin synthesis could not be demonstrated and generally enhanced protein synthesis was not detectable [30]. Is there evidence for sulfonylurea-induced apoptosis? While positive evidence was obtained in in vitro studies [31, 32], the induction of apoptosis could not be verified in vivo when mice were treated with glibenclamide at a maximally effective concentration in a slow-release formulation [33]. Interestingly, the practically complete closure of $\mathrm{K}_{\mathrm{ATP}}$ channels in the beta cells during the treatment led to glucose intolerance similar to the phenotype of Sur1 knockout mice. Because this effect was completely reversible, it appears that secondary failure during sulfonylurea therapy may be more functional than structural. These considerations concur with an in vitro study in which beta cell damage caused by tolbutamide and a number of imidazolines did not correlate with insulinotropic efficacy, leading to the conclusion that a $\mathrm{K}_{\text {ATP }}$ channel block per se is not toxic to beta cells [34].

The complexity of the relation between increased insulin secretion and loss of beta cell mass is exemplified by the $o b / o b$ mouse, in which insulin resistance is largely overcome by massively increased insulin secretion; nevertheless, the islets do not degenerate but rather become grossly hypertrophic and remain so for the rest of the animal's lifetime [35]. Thus, a long-term increase in insulin secretion, even if the increase is large, is not necessarily associated with a deterioration of function and a loss of beta cell mass.

\section{The concept of beta cell rest}

Another piece of evidence cited in support of the hypersecretion hypothesis comes from work on the overstimulated beta cell. A $48 \mathrm{~h}$ infusion to establish a glucose concentration of $20 \mathrm{mmol} / \mathrm{l}$ led to a nearly complete loss of secretory responsiveness upon renewed stimulation by pancreas perfusion. When glucose infusion was accompa- nied by the application of diazoxide to prevent the glucoseinduced secretion, the subsequent response of the perfused pancreas to glucose was largely preserved [12]. Inhibition of secretion by other mechanisms, e.g. somatostatin, had in principle the same beneficial effect. These observations led to the concept of preserving beta cell function in type 2 diabetes by repeatedly inducing phases of beta cell rest. In practice this means blocking insulin secretion during the night so that the beta cells will be capable of a good response during the day.

However, clinical trials so far have not yielded the expected results. A bedtime treatment with diazoxide had no significant side effects and tended to improve beta cell function, but failed to improve metabolic control. Another study showed that treatment with diazoxide was feasible without insulin supplementation, but did not improve insulin secretion [36]. One reason for the modest success of the beta cell rest concept in clinical practice may lie in the difference between the glucose concentration used in the infusion experiments and those typically present in a patient with type 2 diabetes. Also, the protection against overstimulation was achieved in animals with a normally responding endocrine pancreas, whereas at least some type 2 diabetic patients have a primary defect in stimulus-secretion coupling, which may distort the beneficial effect of beta cell rest. Interesting as the concept is, an overview of current clinical data does not lend much support to the notion that the use of insulinotropic drugs as such is detrimental to the beta cell [37].

\section{New insulinotropic drugs}

The hypothesis that a drug that promotes $\mathrm{K}_{\mathrm{ATP}}$ channel closure is in principle toxic to the beta cell as a consequence of an increased cytosolic calcium concentration is attractive in that it covers at least some of the mechanisms underlying glucotoxicity. The limitations become obvious when considering the insulinotropic mechanism of action of glucagon-like peptide 1 (GLP-1). GLP-1 has been identified as a main component of the enteroinsular axis [38]. While the therapeutic effect of GLP-1 and its analogues in type 2 diabetes comprises a number of extrapancreatic effects, of which the anorexigenic effect is particularly prominent, the enhancement of glucoseinduced insulin release is undoubtedly of central importance [39]. After all, the difference in insulinotropic effects of oral and intravenous glucose application was the starting point for the discovery of the incretin system.

Like all receptors of the glucagon family, the GLP-1 receptor is coupled to cyclic AMP generation via a Gs protein. This then activates protein kinase A-dependent signalling and exchange protein directly activated by cAMP 
(EPAC)-dependent signalling. Consequently, the exocytotic machinery is activated directly; the cytosolic $\mathrm{Ca}^{2+}$ concentration is increased by promoting release from internal $\mathrm{Ca}^{2+}$ stores and the $\mathrm{K}_{\text {ATP }}$ channel open probability is decreased, thereby stimulating the electrical activity of the beta cell. Additionally, the insulin biosynthesis is activated by a pancreatic and duodenal homeobox 1 (PDX1)-dependent pathway [40]. From the point of view of the hypersecretion hypothesis, GLP-1 exerts a number of potentially detrimental effects on the beta cell. However, there is currently no evidence that application of GLP-1, dipeptidyl peptidase 4 (DPP IV) inhibitors or longer-acting GLP-1 analogues is associated with a loss of beta cell mass. Rather, preservation of beta cell mass has been observed in animals, while the effects upon human islets requires further verification [40].

The glucose-phosphorylating enzyme glucokinase plays a key role in the concept of metabolic stimulus-secretion coupling as it acts as the glucose sensor of the beta cell. During the last 10 years small-molecule compounds have been developed as activators of glucokinase enzyme activity [41]. These compounds shift glucokinase to its active conformation, which facilitates binding and phosphorylation of the substrate glucose [42]. In a dosedependent manner, all glucokinase activators increase the affinity for glucose while only some are additionally able to increase the $V_{\max }$ of the enzyme [41]. Glucokinase (GK) activators induced insulinotropic effects, and a decrease in hepatic glucose production was observed in animal models of type 2 diabetes and diet-induced obesity [41]. In comparison with sulfonylureas, GK activators have insulinotropic effects that follow metabolic stimulus-secretion coupling by glucose [42]. This means that the amplifying pathways of exocytosis, insulin biosynthesis and beta cell mass are positively modulated by GK activators. Treatment of glucokinase-haploinsufficient mice with a GK activator improved glucose tolerance after a high-fat diet but apparently had no synergistic effect on beta cell mass, although short-term treatment with the GK activatorinduced beta cell proliferation [41]. There remains a potential risk of hypoglycaemia because GK activators dose-dependently induce a shift to the left in glucose responsiveness to subphysiological concentrations, which is in line with activating glucokinase mutations causing the persistent hyperinsulinaemic hypoglycaemia of infancy (PHHI)-syndrome [41, 42]. It should be kept in mind that currently available GK activators represent a chemically heterogeneous class of compounds whose therapeutic action will crucially depend upon both the nature and extent of GK activation and pharmacokinetic properties determining the effective concentrations in liver and beta cells.

Imidazolines were described as small-molecule insulinotropic compounds with GLP-1-like characteristics, in that their insulinotropic effect would require the presence of a stimulatory glucose concentration [43]. A major problem in their development so far has been that the hypothetical imidazoline receptor could not be identified at the molecular level. Some researchers have concluded that the insulinotropic effect is entirely due to a direct $\mathrm{K}_{\mathrm{ATP}}$ channel block and that by inference no imidazoline receptor exists [44]. While this argument has been weakened by the existence of imidazoline compounds which enhance insulin secretion without blocking $\mathrm{K}_{\mathrm{ATP}}$ channels [45], the molecular target of these second-generation imidazolines has remained elusive. A major difficulty consists in the dilemma that the imidazoline ring is apparently not a pharmacophore, making this group much less well defined than the comparatively homogeneous group of sulfonylureas [46]. In addition to the insulinotropic effect, some compounds of this group exert an antiapoptotic effect on beta cells, which ideally could help preserve beta cell mass. Unfortunately, the underlying mechanism is even less well understood than that of the insulinotropic effect [47].

\section{Conclusions and perspectives}

While there is evidence from basic research that stimulation of insulin secretion and $\mathrm{K}_{\mathrm{ATP}}$ channel closure is related to beta cell toxicity, on balance the evidence is not in favour of this contention. At the clinical level, the concept that hyperreactivity of the endocrine pancreas paves the way for type 2 diabetes is even less convincing. It should be noted that the effects of sulfonylureas on beta cells are still not known to their full extent. So questions about their effects on the exocytotic machinery and on mitochondrial energetics are still unanswered. Also, we have to admit that the pathogenesis of type 2 diabetes is not yet fully understood. The unexpected benefits of bariatric surgery suggest that relevant pathogenetic factors, some of them affecting beta cell function, are still awaiting discovery [48].

Is the pharmacological stimulation of insulin secretion too much of a good thing? Unsurprisingly, this is the case when hypoglycaemia results from the use of glucoselowering drugs. Apparently, in elderly patients with macrovascular disease the risks associated with the attempt to achieve near-normal $\mathrm{HbA}_{1 \mathrm{c}}$ values outweigh the potential gains [49]. In addition, the view has gained ground that correction of hyperglycaemia might be less relevant than correcting the other components of the metabolic syndrome. Recently published data on the 10 year follow-up of the UKPDS leave little doubt that blood glucose normalisation is important in the therapy of type 2 diabetes [50]. In our view, the development of an oral glucose-lowering drug that reconstructs the defective insulin secretion profile without inducing hypoglycaemia is still a worthwhile goal of clinical and preclinical research. 
Duality of interest The authors declare that there is no duality of interest associated with this manuscript.

\section{References}

1. Pfeiffer EF, Schoffling K, Steigerwald H, Treser G, Otto M (1957) Problem of secondary failure in the oral treatment of diabetes mellitus. Dtsch Med Wochenschr 82:1528-1531 (article in German)

2. Groop LC, Pelkonen R, Koskimies S, Bottazzo GF, Doniach D (1986) Secondary failure to treatment with oral antidiabetic agents in non-insulin-dependent diabetes. Diab Care 9:129-133

3. U.K. Prospective Diabetes Study Group (1995) U.K. prospective diabetes study 16. Overview of 6 years' therapy of type II diabetes: a progressive disease. Diabetes 44:1249-1258

4. Turner RC, Cull CA, Frighi V, Holman RR (1999) Glycemic control with diet, sulfonylurea, metformin, or insulin in patients with type 2 diabetes mellitus: progressive requirement for multiple therapies (UKPDS 49). UK Prospective Diabetes Study (UKPDS) Group. JAMA 281:2005-2012

5. van Haeften TW (2002) Early disturbances in insulin secretion in the development of type 2 diabetes mellitus. Mol Cell Endocrinol 197:197-204

6. Aston-Mourney K, Proietto J, Morahan G, Andrikopoulos S (2008) Too much of a good thing: why it is bad to stimulate the beta cell to secrete insulin. Diabetologia 51:540-545

7. Glaser B, Kesavan P, Heyman M et al (1998) Familial hyperinsulinism caused by an activating glucokinase mutation. N Engl J Med 338:226-230

8. Osbak KK, Colclough K, Saint-Martin C et al (2009) Update on mutations in glucokinase (GCK), which cause maturity-onset diabetes of the young, permanent neonatal diabetes, and hyperinsulinemic hypoglycemia. Hum Mutat 30:1512-1526

9. Lortz S, Gurgul-Convey E, Lenzen S, Tiedge M (2005) Importance of mitochondrial superoxide dismutase expression in insulin-producing cells for the toxicity of reactive oxygen species and proinflammatory cytokines. Diabetologia 48:1541-1548

10. Eizirik DL, Cardozo AK, Cnop M (2008) The role for endoplasmic reticulum stress in diabetes mellitus. Endocr Rev 29:42-61

11. Kahn SE, Haffner SM, Heise MA et al (2006) Glycemic durability of rosiglitazone, metformin, or glyburide monotherapy. N Engl J Med 355:2427-2443

12. Grill V, Bjorklund A (2001) Overstimulation and beta-cell function. Diabetes 50(Suppl 1):S122-S124

13. Reaven GM (1988) Banting lecture 1988. Role of insulin resistance in human disease. Diabetes 37:1595-1607

14. Reaven GM (2005) Insulin resistance, the insulin resistance syndrome, and cardiovascular disease. Panminerva Med 47:201-210

15. Stadler M, Pacini G, Petrie J, Luger A, Anderwald C (2009) Beta cell (dys)function in non-diabetic offspring of diabetic patients. Diabetologia 52:2435-2444

16. Perry JR, Frayling TM (2008) New gene variants alter type 2 diabetes risk predominantly through reduced beta-cell function. Curr Opin Clin Nutr Metab Care 11:371-377

17. Ferrannini E (2007) Metabolic syndrome: a solution in search of a problem. J Clin Endocrinol Metab 92:396-398

18. Prentki M, Nolan CJ (2006) Islet beta cell failure in type 2 diabetes. J Clin Invest 116:1802-1812

19. Poitout V, Robertson RP (2002) Minireview: secondary beta-cell failure in type 2 diabetes - a convergence of glucotoxicity and lipotoxicity. Endocrinology 143:339-342

20. Rustenbeck I (2002) Desensitization of insulin secretion. Biochem Pharmacol 63:1921-1935
21. Butler AE, Janson J, Bonner-Weir S, Ritzel R, Rizza RA, Butler PC (2003) Beta-cell deficit and increased beta-cell apoptosis in humans with type 2 diabetes. Diabetes 52:102-110

22. Rahier J, Guiot Y, Goebbels RM, Sempoux C, Henquin JC (2008) Pancreatic beta-cell mass in European subjects with type 2 diabetes. Diabetes Obes Metab 10(Suppl 4):32-42

23. Marchetti P, Bugliani M, Lupi R et al (2007) The endoplasmic reticulum in pancreatic beta cells of type 2 diabetes patients. Diabetologia 50:2486-2494

24. Davis SN, Granner DK (1996) Insulin, oral hypoglycaemic agents and the pharmacology of the endocrine pancreas. In: Hardman JG, Goodman Gilman A, Limbird LE (eds) The pharmacological basis of therapeutics. McGraw-Hill, New York, pp 1487-1517

25. Feldman JM, Lebovitz HE (1969) Appraisal of the extrapancreatic actions of sulfonylureas. Arch Intern Med 123:314-322

26. Shapiro ET, van Cauter E, Tillil H et al (1989) Glyburide enhances the responsiveness of the beta-cell to glucose but does not correct the abnormal patterns of insulin secretion in noninsulin-dependent diabetes mellitus. J Clin Endocrinol Metab 69:571-576

27. Panten U, Zünkler BJ, Scheit S, Kirchhoff K, Lenzen S (1986) Regulation of energy metabolism in pancreatic islets by glucose and tolbutamide. Diabetologia 29:648-654

28. Henquin JC (1998) A minimum of fuel is necessary for tolbutamide to mimic the effects of glucose on electrical activity in pancreatic beta-cells. Endocrinology 139:993-998

29. Birkeland KI, Furuseth K, Melander A, Mowinckel P, Vaaler S (1994) Long-term randomized placebo-controlled double-blind therapeutic comparison of glipizide and glyburide. Glycemic control and insulin secretion during 15 months. Diab Care 17:45-49

30. Schauder P, Arends J, Frerichs H (1977) Onset and reversibility of changes in secretory function and composition of isolated rat pancreatic islets following long-term administrationof high or low tolbutamide doses. Metabolism 26:9-15

31. Efanova IB, Zaitsev SV, Zhivotovsky B et al (1998) Glucose and tolbutamide induce apoptosis in pancreatic beta-cells. A process dependent on intracellular $\mathrm{Ca}^{2+}$ concentration. J Biol Chem 273:33501-33507

32. Maedler K, Carr RD, Bosco D, Zuellig RA, Berney T, Donath MY (2005) Sulfonylurea induced beta-cell apoptosis in cultured human islets. J Clin Endocrinol Metab 90:501-506

33. Remedi MS, Nichols CG (2008) Chronic antidiabetic sulfonylureas in vivo: reversible effects on mouse pancreatic beta-cells. PLoS Med 5:e206

34. Rustenbeck I, Krautheim A, Jörns A, Steinfelder HJ (2004) Betacell toxicity of ATP-sensitive $\mathrm{K}^{+}$channel-blocking insulin secretagogues. Biochem Pharmacol 67:1733-1741

35. Hellman B (1965) Studies in obese-hyperglycemic mice. Ann NY Acad Sci 131:541-558

36. Radtke M, Kollind M, Qvigstad E, Grill V (2007) Twelve weeks' treatment with diazoxide without insulin supplementation in type 2 diabetes is feasible but does not improve insulin secretion. Diabet Med 24:172-177

37. Grill V, Radtke M, Qvigstad E, Kollind M, Bjorklund A (2009) Beneficial effects of K-ATP channel openers in diabetes: an update on mechanisms and clinical experiences. Diabetes Obes Metab 11(Suppl 4):143-148

38. Creutzfeldt W, Nauck M (1992) Gut hormones and diabetes mellitus. Diabetes Metab Rev 8:149-177

39. Nauck MA, Heimesaat MM, Orskov C, Holst JJ, Ebert R, Creutzfeldt W (1993) Preserved incretin activity of glucagonlike peptide 1 [7-36 amide] but not of synthetic human gastric inhibitory polypeptide in patients with type-2 diabetes mellitus. J Clin Invest 91:301-307

40. Doyle ME, Egan JM (2007) Mechanisms of action of glucagonlike peptide 1 in the pancreas. Pharmacol Ther 113:546-593 
41. Matschinsky FM (2009) Assessing the potential of glucokinase activators in diabetes therapy. Nat Rev Drug Discov 8:399-416

42. Grimsby J, Matschinsky FM, Grippo JF (2004) Discovery and action of glucokinase activators. In: Matschinsky FM, Magnuson MA (eds) Glucokinase and glycemic disease: from basics to novel therapeutics. Karger, Basel, pp 360-378

43. Morgan NG, Chan SL (2001) Imidazoline binding sites in the endocrine pancreas: can they fulfil their potential as targets for the development of new insulin secretagogues? Curr Pharm Des 7:1413-1431

44. Proks P, Ashcroft FM (1997) Phentolamine block of KATP channels is mediated by Kir6.2. Proc Natl Acad Sci USA 94:11716-11720

45. Efendic S, Efanov AM, Berggren PO, Zaitsev SV (2002) Two generations of insulinotropic imidazoline compounds. Diabetes 51 (Suppl 3):S448-S454
46. Hatlapatka K, Wienbergen A, Kuhne C, Jörns A, Willenborg M, Rustenbeck I (2009) Selective enhancement of nutrient-induced insulin secretion by ATP-sensitive $\mathrm{K}^{+}$channel-blocking imidazolines. J Pharmacol Exp Ther 331:1033-1041

47. Papaccio G, Graziano A, Valiante S, D'Aquino R, Travali S, Nicoletti F (2005) Interleukin (IL)-1 beta toxicity to islet beta cells: efaroxan exerts a complete protection. J Cell Physiol 203:94-102

48. Ferrannini E, Mingrone G (2009) Impact of different bariatric surgical procedures on insulin action and beta-cell function in type 2 diabetes. Diab Care 32:514-520

49. Gerstein HC, Miller ME, Byington RP et al (2008) Effects of intensive glucose lowering in type 2 diabetes. $\mathrm{N}$ Engl $\mathrm{J}$ Med 358:2545-2559

50. Holman RR, Paul SK, Bethel MA, Matthews DR, Neil HA (2008) 10-year follow-up of intensive glucose control in type 2 diabetes. N Engl J Med 359:1577-1589 